\title{
Priorities for people living with dementia: education, counseling, research
}

\author{
Kerstin Stieber Roger \\ Department of Family Social Sciences, \\ Faculty of Human Ecology, University \\ of Manitoba, Winnipeg, Canada
}

Correspondence: Kerstin Stieber Roger Department of Family Social Sciences, Faculty of Human Ecology, University of Manitoba, Winnipeg, Canada Tel +l 2044746354

Email rogerk@cc.umanitoba.ca

\begin{abstract}
Hearing the voices of people living with dementia assists in a better understanding of their experiences. This understanding can pave the way for improved community-based service delivery such as education and counseling, as well as including them more frequently as research participants. The voices of people living with dementia have not been well represented in research, resulting in very few data describing their experiences. This paper describes empirical qualitative data from a study that asked people with Alzheimer's and Huntington's disease about their experiences. Recommendations are provided on education, counseling, and research.
\end{abstract}

Keywords: counseling, dementia, education, family, personhood, research

\section{Background}

Many new (or newly recognized) terminal medical conditions are presenting a more complex end-of-life picture for service providers. This reality challenges the 6-month prognosis commonly associated with cancer. Diabetes, asthma, and multiple sclerosis as well as a wide range of dementias lead to unique end-of-life experiences and can last up to fifteen years after diagnosis. Increasingly, people also want to die at home, changing the focus of their care away from formal care centers to families and the community (CPCA 2002). These factors make evident the increasing need to develop specific care interventions and community-based services for individuals living in community with a wide range of terminal medical conditions, their families, and formal care providers.

Dementia is a brain disorder characterized by progressive memory loss and cognitive dysfunction, which occurs in mid to late life (McKhann et al 1984). Over 30 other types of dementia exist including Alzheimer's and Huntington's disease, vascular dementia, and Korsakoff's. Related diagnoses include cognitive impairment no dementia (CIND), mild cognitive impairment (MCI), a Diagnostic Statistical Manual (DSM-IV-TR) diagnosis of delirium, and other medical conditions (eg, AIDS) that include cognitive decline but that may or may not be dementia related.

According to a study published by the Canadian Study of Health and Aging Working Group (2008), an estimated 97,000 Canadians will develop Alzheimer's or a related disease and an estimated 450,000 Canadians over 65 have Alzheimer's or a related disease. According to an earlier study that number could more than double by 2021 and could triple by 2031 (CSHA 1984). This study also found that $53 \%$ of Canadians knew someone with Alzheimer's disease, while 25\% of Canadians had someone in their family with Alzheimer's disease.

Huntington's disease is an inherited brain disorder which causes cells in specific parts of the brain to die (HSC 2008). About 1 in very 10,000 Canadians has Huntington's disease, but 1 in every 1,000 Canadians is touched by the disease through family and community experiences. Symptoms can include emotional changes, memory loss, and mobility changes similar to those of Alzheimer's disease, and similarly, there is no 
treatment for this condition at this time. Further, the association between mortality and poor cognitive function is well documented (Langley 1995) suggesting the importance of understanding and recommending appropriate end-of-life care for people living with Alzheimer's and Huntington's disease.

\section{Theoretical framework}

The framework of 'personhood' was developed most definitively by Kitwood (1997) in Dementia Reconsidered: The Person Comes First, and he stands out as a ground-breaking researcher investigating the experience of people with dementia as persons. Sabat (2005) has been well known for declaring that researchers and others must listen to the voices of those with dementia. He states that the effect of being diagnosed with dementia may result in the person 'being positioned in advance as being incapacitated', reducing their status of personhood unnecessarily. Keady et al (1999) similarly suggest that the real task of establishing personhood is one of developing the capacity for people with dementia to be seen as contributors to those relationships. Clearly, a growing body of evidence (Clare 2003; Roger 2007) is suggesting that one can listen to people with dementia in a way that can impact the development of clinical interventions, service delivery, and policy development.

Berger (1998) presents a model of lifespan development which implies a 'personhood' approach, although this model is intended for a general population. According to Berger, emotional, physical, and/or cognitive domains are seen as critical for human lifespan development. Berger demonstrates that from conception to death, we each integrate emotions, physical needs, and behaviors into various stages of development. These domains are not diminished as we approach death, according to Berger, but they might change in quality.

For example, emotional aspects of lifespan development include the expression of, or the description of, our emotional responses to events such as happiness, sadness, and anger. Cognitive aspects of lifespan development are those which focus on thought patterns, an analysis of a situation, or a belief - how one thinks about, or values one holds about memory loss may be an example of cognitive activity. Behavioral aspects of lifespan development are observable actions and behaviors. Berger's model will help to frame how people living with dementia continue to experience all three domains associated with lifespan development. Understanding that individuals do experience all three domains even with a terminal medical condition assists in a better understanding of their personhood across the lifespan.
While the 'cause of death' is generally not considered a priority for the work of related service providers, 'cause of death' continues to be socially laden with moral values (eg, AIDS) and can determine the quality of support that some groups might receive. As Wilkinson (2002) states, people with dementia have not felt that they have valuable experiences worth sharing and they have not wanted to come forward and disclose their experiences of this condition. Cotrell (1993) states that in the majority of the research on dementia, people are treated as 'disease entities' rather than people with valuable experiences. One purpose of this paper is to demonstrate that, given a better understanding of the daily lived experience of people living with dementia, we can make suitable changes related to care and service provision. This may in turn also assist in reducing widespread misunderstandings about people living with dementia.

\section{Methodology}

Grounded theory is designed to explore social processes inherent to human interactions, and to uncover beliefs, attitudes, and practices of individuals or groups, as they function in their daily life. This pilot study employed a cross-sectional descriptive-exploratory design based on the tenets of grounded theory in order to explore how people with Alzheimer's and Huntington's disease reflected on their experiences of memory loss. The focus was not to explore how the experience of medical aspects of the diagnosis, but to focus on their subjective experiences of a medical terminal condition that included memory loss as one daily interactive experience. Contributions towards the theory of personhood in tandem with a revised definition of end-of-life are anticipated through the presentation of these data, as well as developing further studies built on the data found here.

The study was conducted in central Canada and participants were selected from three organizations that provide services and programs for people who are living with Alzheimer's or Huntington's disease. Staff selected specific people already well known to them with a diagnosis of either probable Alzheimer's disease or confirmed Huntington's disease, and invited them to attend an initial talk about the study so that they could ask questions about their possible participation. If they were willing to participate in the research, they proceeded to the next step.

According to the ethics protocol, submitted to and approved by the medical ethics review board at the University of Manitoba, an eligibility screen and a consent form signed by the participant and one care provider were required for participation. Therefore, potential participants who fit the criteria, 
and, expressed interest in participating in the study after the initial talk was heard, were asked to undergo a 7-point brief test in order to assess their ability to be interviewed (Katzman et al 1983). The Blessed Orientation Memory Concentration Test (BLOMC) asked potential participants to demonstrate their interviewability by, for example, remembering specific dates, months of the year, or repeating certain phrases. Their participation was then based on acceptable ratings according to the BLOMC. Consent forms were signed both by participants and one selected care provider.

People were excluded from this talk if they did not have a diagnosis of probable Alzheimer's or confirmed Huntington's disease, were not selected by staff (no one who expressed interest was turned away), were unable to converse verbally, hear or speak English, were experiencing significant personal crisis, were younger than 18 , or refused to participate in the study. This selection process resulted in a purposive sample.

\section{Interviews}

Data were gathered through semi-structured, face-to-face interviews by the first author at a location and time selected by the participant lasting between thirty minutes and two hours. Prior to each interview, 4 demographic questions on a participant's age, previous profession, ethnicity, and date of diagnosis were asked. Interview questions were prepared on the basis of identified gaps in the literature review keeping in mind that the goal of the study was to focus on participants' experience of memory loss, their sense of independence and self in relation to significant relationships, and to questions on their thoughts about the future. For example, questions included the following: "what has changed since your diagnosis?', or, 'have your social interactions with people felt different since your diagnosis, and if so, how?' The interview schedule was reviewed in advance by a team of professionals knowledgeable in counseling, memory loss, or end-of-life, further refining the number and type of question. The same interview questions were asked in each interview, although flexibility occurred in the order of the questions, the pace, and when additional probes were seen to be useful.

Two focus groups were scheduled once all individual interviews were completed: one for people with Alzheimer's disease and one for people with Huntington's disease. The two focus groups conducted were used to present initial themes that emerged in the interviews after a preliminary analysis of the data had been done. The focus was to establish whether the themes accurately documented the voices of the participants.
No new questions were added to the focus groups, although probes occurred.

\section{Data analysis}

All interview data were transcribed and reviewed using the qualitative analysis software NVIVO. An inductive analytic approach led to a sequential analysis of each passage of text that was coded and recoded in the context of the broader goal of the study. A comparative analysis between themes occurred throughout the coding process. Two second readers well versed in end-of-life research were selected both to confirm the emergence of themes and to ensure the rigor of the analysis. During this analytic process, it became apparent that the participants experienced their daily lives in a way that reflected Berger's model.

Validity and reliability of the results are understood in the context of qualitative research. Participants were selected in sites they knew well and by staff they trusted, eliciting a more trusting relationship to the interviewer. They were given the opportunity to hear about the study, ask questions, and ensure their own interest in the subject matter over time, and, there were no consequences if they chose not to participate. Validity and reliability was further established by the second readers' reviews, and the recognition that the emerging data in this study directly mirrored both the content and the gaps identified in the literature review.

\section{Participant profiles}

In total, 22 individuals participated in the study (6 men and 14 women) (see Table 1). Nine of the participants were selected from the local day hospital affiliated with a longterm care home (age 80-95); 8 people were selected through the local Alzheimer's Society (age 65-80); 5 people had Huntington's Chorea and were associated with a local community based organization (age 34-60). Participants tended to be younger in the Huntington's sample and older in the day-hospital sample.

The range of previous work/career experiences of the participants was diverse. The type of work participants had engaged in over their lifespan likely influenced both their understanding and perception of memory loss, and, how they engaged with the researcher in the interview. A question about ethnicity was asked. Some participants stated that they were of European descent representing Scottish, French, German, and Polish communities. Two people said they were Jewish, and 2 said they were Mennonite. Four said they were Canadian and 3 did not state an ethnic background. Reports on the dates of diagnosis varied to such an extent 
Table I Participant profiles

\begin{tabular}{|c|c|c|c|c|c|}
\hline $\begin{array}{l}\text { Alzheimer's } \\
\text { Pseudonym }\end{array}$ & Gender & Ethnic & Age & Work experience & $\begin{array}{l}\text { Suggested date } \\
\text { of diagnosis }\end{array}$ \\
\hline Evan & $M$ & Canadian & 75 & Forester & 2002 \\
\hline Nora & $\mathrm{F}$ & $\mathrm{n} / \mathrm{a}$ & 65 & Professional work & 2003 \\
\hline Ivanna & $\mathrm{F}$ & $\mathrm{n} / \mathrm{a}$ & 78 & Raised family & 2004 \\
\hline Erika & $\mathrm{F}$ & English & 78 & & 2004 \\
\hline Bert & $M$ & Jewish & 78 & Business/Salesman & 2000 \\
\hline Luc & $M$ & Franco-Manitoban & 73 & Crane operator & 'a few years' \\
\hline Chris & $M$ & Poland & 68 & Business owner & 6 years ago \\
\hline Emma & $\mathrm{F}$ & Scottish & 73 & Sales at Eaton's & 'long ago' \\
\hline \multicolumn{6}{|l|}{ Huntington's } \\
\hline \multicolumn{6}{|l|}{ Pseudonym } \\
\hline Nigella & $\mathrm{F}$ & Ukranian & 58 & Teacher & 1995 \\
\hline Trish & $\mathrm{F}$ & Canadian & 34 & Used to work & 2002 \\
\hline Yvonne & $\mathrm{F}$ & Mennonite & 60 & Teacher & 1994 \\
\hline Adrienne & $\mathrm{F}$ & Eng./French & 58 & Professional & 2001 \\
\hline Rayna & $\mathrm{F}$ & Scottish & 56 & & 1995 \\
\hline \multicolumn{6}{|c|}{ Health Centre Day } \\
\hline \multicolumn{6}{|c|}{ Hospital Pseudonym } \\
\hline Beth & $\mathrm{F}$ & Mennonite & 58 & $\mathrm{n} / \mathrm{a}$ & Long ago \\
\hline Alicia & $\mathrm{F}$ & Jewish & 80 & Legal/receptionist & Don't know \\
\hline Brian & M & Irish & 90 & Farmer, technician & $\mathrm{n} / \mathrm{a}$ \\
\hline Ellie & $\mathrm{F}$ & Canadian & 86 & Sales clerk & 'A while ago' \\
\hline Maria & $\mathrm{F}$ & Ukranian & 86 & Raised kids & $\mathrm{n} / \mathrm{a}$ \\
\hline Katrin & $f$ & Franco-Canadian & 85 & $\mathrm{n} / \mathrm{a}$ & 'My own evaluation' \\
\hline
\end{tabular}

that more data would be required to better understand any analytic value.

Recognizing the broad range and socio-demographic variation in participant's backgrounds contributes to the richness of the empirical data. At the same time, the study was designed to understand better subjective experiences of memory loss, and not to identify correlations between diagnoses, articulated experiences of memory loss, and socio-demographic descriptors. Another study is recommended for that purpose.

\section{Findings}

Berger's three primary domains across the lifespan include emotional, cognitive, and behavioral. This discussion will make reference to how the participant's narratives represented each of these three domains.

\section{Emotional}

Berger (1998) stated that the emotional domain is a significant aspect of lifespan development. Participants in this study were able to both discuss feelings about their situation and express those feelings in the course of the interviews. For example, the loss of one-to-one friendships had occurred for most participants, resulting not only in a loss of interpersonal contact and emotional fulfillment, but also in a loss of a public and social identity. This recognition led to sadness for many participants. For example, Nigella expressed significant sadness through her tears about the possible pain she was inflicting on her family due to her frequent mood swings. She was aware of these emotions in retrospect, aware of their impact on her family, and this impact now brought her sadness. Another participant, Ivanna, noted that since her diagnosis, her friends visited less often, and she similarly expressed regret about these losses in her social life and to her personal well-being. Alternatively, Erika was not emotional about the same type of changes and she suggested that memory losses were more an issue for others than for herself. Other participants spoke with joy about a new and positive aspect to this diagnosis - support groups for people 
with similar experiences. For example, getting together with people living with dementia was a positive addition to many participant lives both in regards to their social life and their personal well-being. Ivanna states:

They are a good group and we have a lot of laughs too over certain things that ... because some, as I say, one of the ladies is a little further on, you know, we can laugh about it.

Ivanna demonstrates an ability to reflect on losses and gains: new bonds with people with similar conditions can be forged and bring her joy. These participant examples provide the reader with an alternative view to traditional interpretations of the experience of terminal medical conditions: in this case, they suggest that participants can reflect on their emotional experiences of memory loss after the fact, they do have feelings about the impact of these experiences on others, and they were insightful about the changes to their social well-being. These observations reflect Berger's emotional domain essential as part of all life span development.

\section{Cognitive}

According to Berger (1998), lifespan development includes a person's ability to analyze their situation in a way that reveals particular thought patterns, personalities, and an evaluation of their own personal and social histories. This is the cognitive domain. This was evident in the participants in these interviews as follows. Analyzing one's family history in light of his new terminal diagnosis was a common practice for participants as they thought about their own situations. Dorothy recalls:

Like my dad [had it]. They didn't call it Alzheimer's in those days. I forget what they called it. See I can't remember that. Like, he got quite forgetful. He didn't always know what was going on, so I figured it's just maybe hereditary. I took after my dad instead of my mother.

Dorothy is reflecting on her father's condition demonstrating a comparative analysis with herself and her father 'back then'. Thinking through previous values held about memory loss contributed towards how Dorothy defined her own current situation. Participants also demonstrated how they thought about decisions they needed to make. For example, Evan needed to cut back on singing in the choir, and here he analyzes how this decision occurred:

And everybody talked at once...I got lost. I zero in on the food. Well that's the only way I can do it, because I can't talk and ... I mean, not only that sort of thing. In any group you have difficulty following along because your brain isn't working as well.
Thinking about the future occurred as well to varying degrees. While some participants reflected only on a short-term future, for example by referring to the decision that they would not be able to use their credit card in the near future due to an inability to manage their current purchases; others reflected on longer term future moments such as an actual death, or, being at 'that' point (not speaking or recognizing others). Despite increasing memory loss, Erika imagines the following scenario about her own possible future, 'Well, I wish to stay healthy. At least my mind is healthy, so that I can be productive'. This was an interesting statement as she reflected on her current reality of memory loss. Some participants spoke about religion or faith as contributors towards their thoughts about a possible future self. Faith reflects a belief about the self in the world in such cases. Beth states:

God alone knows about my future. This is the day the Lord has made. Let us rejoice and be glad. I say that verse many times. Then you have to go back to what you pray, what you said, what God said. And so, I keep on doing that. I trust the Lord.

In some cases, a possible future self was also associated with a world diminished by other aspects associated with aging, and not specifically with memory loss. Here, not being able to see friends because the winter roads were icy, and public transportation was not effective, was a kind of future not associated specifically with memory loss but with aging in general. These participants demonstrated an ability to think both into their families' past and their own future, comparing and contrasting these situations with their own.

\section{Behavioral}

Berger (1998) refers to behaviors as observable activities, and suggests that this is the third and final domain required for development across the lifespan. Participant insights into their own disabling declines and losses included accounts of specific proactive strategies. Rayna expresses an alternative here to a previous activity:

Well, my husband does the cooking and I don't like that part. Interviewer: You miss doing cooking?

Yeah, I do. And I think, well sure I could do the cooking.

And I think, well maybe I'll do the vegetables. Yeah.

Rayna is able to reflect on a familiar activity she has often enjoyed doing in the past, she reflects that she is no longer able to engage in this activity, and she demonstrates that she has considered and selected an alternative, 'doing the 
vegetables'. Other strategies were developed and discussed by participants. Nigella spoke of having lists for her tasks around the house, and that she had to develop lists of lists as time went by. She laughed how these were posted on each door, in the back and the front, and how she had to sometimes remember where she had now placed a particular list. Yet her development of these lists fundamentally contributed towards her sense of independence and well-being. Some participants reflected on living with other physical disabilities along with dementia. For example, Beth was also blind and hard of hearing. She found it particularly 'funny' that her brother, who is neither living with dementia nor blind, provided her with a long lecture about how to resolve her difficulties in her home due to her disabilities. He provided her with strategies to alphabetize the spices, and, how to get the garbage out. She suggested that his ideas for a condition he knew nothing about may be useless. Beth's story highlights that people with dementia are able to reflect not only on their memory losses, they can also reflect on their own strategies used to retain an aspect of function, and, in Beth's case, she was able to compare these strategies to the suggestions of others. These examples show that participants were able to reflect on their own actions and behaviors - what they liked and did not like - and their attempts to make changes to those behaviors as memory losses increased.

\section{Discussion}

The three domains of emotion, cognition, and behavior are suggested as key to lifespan development by Berger (1998) and are seen in this discussion in the example of participant's experiences living with these two examples of a terminal medical diagnosis. Hearing the voices of people living with Alzheimer's and Huntington's disease helps us to understand that emotions, cognition, and behavioral aspects of their personhood exist alongside the medical aspects of dementia. These data begin to demonstrate that the lives of these participants do not become less meaningful by their own declaration as their efforts to deal with dementia, to engage with others, and to develop new strategies continue. Their declines do not put an end to laughter, making meaning, and cherishing important relationships; and just as importantly, the declines do not always lead participants to cope as well as they may have wanted. It is also evident from these data that participants responded to the interview with personal awareness and sensitivity not only about their own memory loss, but also about strategies to accommodate those changes, and their experiences with changing relationships. They were suitable and eager research participants. By documenting the participant's stories, they offer their individual personalities, rich histories, and unique ways of handling challenging situations. In this sense, Berger's model applied to their narratives frame how they continue to experience the three domains associated with lifespan development despite a terminal medical diagnosis.

\section{Recommendations}

With the predicted growth in the population of aging people, and the increased diagnosis of new terminal medical conditions, the demands on these individuals and intergenerational care providers will change significantly. This new demographic will impact the career paths of younger generations as we provide services using new technologies and new medical advances. It is imperative that researchers seek to better understand the social aspects of this condition, as these demographic and social changes occur. Education in an ongoing manner, new counseling programs, and research that investigates the gaps will continue to be essential.

\section{Education}

It is evident that understanding the experiences of these participants can benefit social service program development for people living with dementia in the community. While dementia has been viewed primarily with a biomedical lens in the past, well planned social services are increasingly being seen to be able to maintain or even improve upon an individual's independence in the community. For example, educating individuals with a new diagnosis about the strategies employed by others already living with dementia can prove helpful and possibly preventative (eg, accidents). Understanding that individual family histories and differences may contribute towards the development of their coping skills may reduce the conclusion that emotions are primarily now due to the illness itself. With evidence as to individual's abilities (rather than a focus on their disabilities), specific educational programs for care providers can be developed. As individuals and their care providers learn to promote independence given newly learned strategies, an added benefit may be reducing the stigma that people living with dementia are only vulnerable and needy individuals.

\section{Counseling}

Participants spoke about the inevitable (and undesirable) social changes they experienced. Asking about these experiences in the context of this study evoked their need to continue to talk about and process these changes. Sadness 


\begin{tabular}{lll}
\hline Theory/Research & Education & Counseling \\
\hline $\begin{array}{l}\text { Investigating the experience of } \\
\text { those living with dementia, to better } \\
\text { understand their insights }\end{array}$ & $\begin{array}{l}\text { Education for formal and informal care } \\
\text { providers regarding the abilities and } \\
\text { opportunities for independence of } \\
\text { people with dementia. }\end{array}$ & $\begin{array}{l}\text { Counseling programs designed for those living } \\
\text { with dementia to reduce grief, sadness, and } \\
\text { experiences of stigma }\end{array}$ \\
$\begin{array}{l}\text { - Investigating emotional, cognitive, } \\
\text { and behavioral responses of people }\end{array}$ & Translating new research findings for all & Counseling programs designed for family \\
living with dementia & A better understanding of people's & members involved in daily care to alleviate \\
mith decision-making processes that & daily lived experience can assist in & stress \\
lead to ethical concerns & reducing stigma & Counseling for paid care professionals (nurses, \\
social workers, psychologists) experiencing & stress and burn out \\
\hline
\end{tabular}

and joy was communicated related not only to the disease but also related to the social aspects of their experience. It was apparent that these participants were keen to have their voices heard and their feelings understood, and they stated that this had not happened often in official or formal settings. Further, it was previously thought that counseling could not help individuals with a diagnosis associated with dementia. Counseling programs are required not only for this population, who can benefit from exploring their experiences, but also for their families and for paid care professionals.

\section{Research}

Understanding personhood is still a new focus for researchers (Cotrell and Schulz 1993; Roger 2006; Wilkinson 2002). Traditionally, people with dementia have not been interviewed for the purpose of research, although this is changing. Certainly, applying new approaches to data collection may result in more useful data. The researcher may be required to speak slowly in some cases, to repeat a question, to probe more deeply into a particular topic. However, a respectful researcher would keep these skills in mind for any population of interest. New data on this group of people can likely support more appropriate pain management, improved strategies for end-of-life decision-making for families, and a wide range of clinical interventions used in long term care homes. New data can benefit formal and informal care professionals as they are required to increasingly support people with dementia, and make decisions on their behalf. This is most relevant as the question of a person's competence increases with time. In this regard, increasing the visibility of people living with dementia in the context of research will offer improved insights and further research questions.

Based on the empirical data that this study has elicited, the following recommendations can be made:

\section{Disclosures}

The author has no conflicts of interest to disclose.

\section{References}

Berger K. 1998. The developing person through the life span (4th ed). New York: Worth Publishers.

[CPCA] Canadian Palliative Care Association. 2002. Public communication [online]. http://www.chpca.net/home.htm.

Canadian Study of Health and Aging Working Group. 2000. The incidence of dementia in Canada. Neurology, 55: 66-73.

[CSHA] Canadian Study of Health and Aging Group. 1994. Canadian study of health and aging, Ottawa: Canada.

Clare L. 2003. Managing threats to self. Soc Sci Med, 57:1017-29.

Cotrell V, Schulz R. 1993. The perspective of the patient with Alzheimer's disease: a neglected dimension of dementia research. Gerontologist, 33:205-11.

Doka K. 2002. Disenfranchised grief. In Doka KJ (Ed.). Living with grief: loss in later life. Washington: Hospice Foundation of America.

Foti ME. 2003. Do it your way: A demonstration project on end of life care for persons with serious mental illness. J Palliat Med, 6:661-9.

[HSC] Huntington's Society of Canada. 2008. Public communication [online]. http://www.huntingtonsociety.ca/english/content/?page=91.

Katzman R, Brown T, Fuld P, et al. 1983. Validation of a short orientation memory concentration test of cognitive impairment. Am J Psychiatry, 140:734-9.

Keady J, Gilliard J, Evers C, et al. 1999. The DIAL-log study: support in the early stages of dementia. Br J Nurs, 8:432-6.

Keady J. 2005. The wrong shoes: living with memory loss. Nurs Older People, 17:36-7.

Kitwood T. 1997. Dementia reconsidered: the person comes first. Buckingham: Open University Press.

Langley AM. 1995. The mortality of mental illness in older age. Rev Clin Gerontol, 5:103-12.

Lindgren CL, Connelly CT, Gaspar HL. 1999. Grief in spouse and children caregivers of dementia patients. West J Nurs Res, 21:521-37.

Loos C, Bowd A. 1997. Caregivers of persons with Alzheimer's disease: some neglected implications of the experience of personal loss and grief. Death Stud, 21:501-14.

McKhann G, Drachman D, Folstein M. 1984. Clinical diagnosis of Alzheimer's disease: report of the NINCHDS-ADRDA work group under the auspices of Department of Health and Human Services Task Force on Alzheimer's disease. Neurology, 34:939-44.

Meuser TM, Marwit SJ. 2001. A comprehensive, stage-sensitive model of grief in dementia caregiving. Gerontologist, 41:658-70.

Roger K. 2007. It's a problem for other people, because i am seen as a nuisance'. Alzheimer's Care Quarterly, 8:17-25.

Sabat S. 2005. Capacity for decision making in Alzheimer's disease: selfhood, positioning, and semiotic people. Aust NZ J Psychiatry, 39:1030-5.

Wilkinson H. 2002. The perspectives of people with dementia. London: Jessica Kingsley Publishers. 
